\title{
La autosostenibilidad moral de las sociedades liberales contemporáneas
}

\author{
PABLO LÓPEZ PIETSCH \\ Universidad Autónoma de Madrid
}

¿Socava una sociedad liberal los fundamentos de su propia existencia? A la larga, el hecho de dar rienda suelta a un «individualismo desmedidon y un «desbocado egoísmo» de los ciudadanos, ino tendrá que conducir forzosamente a una erosión del propio orden social que tan amplias libertades concede? Y en este sentido, instituciones centrales del orden liberal como el Estado de Derecho, la democracia representativa o el libre mercado, ¿no estarân acaso sembrando la semilla de su propia destrucción? ${ }^{1}$.

Desde luego que sí, es la respuesta que suele escucharse desde posiciones comunitaristas, e incluso por parte de quienes, sin pertenecer a esta corriente, comparten con ella el diagnóstico del carácter autodestructivo de una sociedad liberal plenamente secularizada. No necesariamente es, en cambio, la conclusión a la que llega el sociólogo alemán Michacl Baurmann en El mercado de la virtud ${ }^{2}$. Al contrario: la tesis central defendida en este libro es que bajo determinadas condiciones empíricas un orden social liberal no sólo no destruyc, sino que genera por sí solo el ingrediente de virtud cívica y compromiso público de los ciudadanos que resulta indispensable para la preservación de sus instituciones.

No obstante, el autor coincide con los críticos del liberalismo en las siguientes dos apreciaciones: primero, en que no es posible un orden social liberal estable si los ciudadanos utilizan sus libertades exclusivamente para buscar su propia ventaja personal más inmediata y no contribuyen desinteresadamente al sostenimiento de sus instituciones ${ }^{3}$, y segundo, en que, en contra de la tesis clásica del doux commerce, el tipo de interacciones sociales que se producen en el mercado económico no puede generar la moralidad cívica necesaria para ese fin. Lo que sucede es que de la aceptación de estas dos premisas no se deduce como conclusión el carácter autodestructivo de las sociedades liberales. El error de los críticos consistiría en fijarse exclusivamente en la dinámica competitiva inherente al orden liberal cuando resulta que la libre persecucion de los propios intereses individuales es sólo una de las estrategias de acción posibles dentro de este orden social. Al mismo tiempo, y como rasgo no menos distintivo, está también garantizada la libertad de asociación, que permite adoptar una estrategia cooperativa y perseguir conjuntamente con otros toda suerte de intereses comunes, ya sean de índole económica, política, religiosa, cultural o ideal. Pues bien, para Baurmann estas empresas cooperativas, por su peculiar estructura interna, precisan de personas moralmente íntegras que se comprometan de modo fiable con aquellos bienes colectivos que sean de su interés. La posibilidad de beneficiarse de la participación en empresas cooperativas supone en este sentido un incentivo para desarrollar una personalidad moral idónea para la cooperación. Pero una persona moralmente idónea para participar en una empresa cooperativa resulta reunir también las condiciones necesarias y suficientes para comprometerse con el sostenimiento del propio orden social de libertad que le posibilita estas estrategias.

De esta forma, la libre persecución asociada de los propios intereses puede pro- 
ducir ese mínimo de moralidad y compromiso cívico indispensable. El mecanismo consistiria en una suerte de mano invisible generadora de moralidad. Del mismo modo en que en un mercado económico no distorsionado la libre persecución de los intereses individuales conduce, de forma involuntaria, a la consecución de un bien colectivo como es la eficiencia en la asignación de los recursos, en un orden social de libertad podría operar un mercado de la virtud que condujera a que un número suficientemente elevado de ciudadanos adoptara, en su propio interés, un genuino punto de vista moral. $Y$ una de las consecuencias de esta adopción autointeresada de una conducta moral sería la participación equitativa en el sostenimiento de las instituciones del orden social liberal.

Si esta tesis, que llamaré de la autosostenibilidad moral de la sociedad liberal, fuera correcta, ello permitiría cuestionar dos afirmaciones que no por tener tintes de rancio conservadurismo y ser empiricamente improbables se escuchan con menor frecuencia: la primera es que si nuestras sociedades liberales aún se mantienen en pie, a pesar de su constante erosión por el individualismo, es porque todavia no están plenamente secularizadas; en realidad viven de una herencia axiológica y cultural premoderna que estamos dilapidando y que pronto se habrá agotado. $Y$ la segunda es que, en consecuencia, es necesario un rearme ideológico y moral que restablezca ese mínimo de cohesión social que el individualismo y materialismo de las sociedades occidentales amenazan con destruir. Por contra, de ser certero el planteamiento de Baurmann, lo pertinente sería asegurar las condiciones para que el mercado de la virtud pudiera funcionar adecuadamente de modo tal que siguiera estando en el interés individual de los propioś ciudadanos desarrollar disposiciones que implicaran, como efecto secundario, su compromiso con el propio orden social.
Esta fundamentación de una actitud moral a partir de los propios intereses personales parcce ofrecer, por lo demás, una base algo más fiable que la que podría proporcionar cualquier campaña de moralización ciudadana.

Sin embargo, el planteamiento del sociólogo alemán ${ }^{4}$ se encamina por una senda erizada de dificultades. No sólo ha de hacer frente al reto comunitarista y neoconservador. Para llegar a buen puerto tendrá que superar, sobre todo, los obstáculos que se le oponen descle la amplísima literatura sobre el abismo existente entre racionalidad individual y racionalidad colectiva. Y tendrá que demostrar, por tanto, de qué manera un individuo que se orienta racionalmente por sus propios, y sólo por sus propios intereses, puede, no obstante, contribuir «desinteresadamente» a un bien colectivo. Lo que sigue a continuación es un recorrido por los principales pasos del razonamiento desarrollado por Baurmann para, en el último apartado, hacer referencia a algunas interrogantes que su análisis suscita.

\section{El modelo del homo sapiens}

La primera decisión a adoptar es la del modelo de actor social que se va a emplear en el análisis. No puede ser el modelo del homo economicus, puesto que, por definỉción, excluye la adopción de comportamientos genuinamente morales. Pero tampoco puede solucionarse el problema por vía estipulativa, adoptando un modelo de comportamiento como el del homo sociologicus, que incluye ya entre sus especificaciones el actuar moral. Si no se quiere frustrar el objeto de la investigación, el actor deberá perseguir exclusivamente sus propios intereses, sin poder recurrir a motivaciones trascendentes de su conducta.

El modelo al que recurre Baurmann es el del maximizador disposicional de utilidad, 
es decir, aquel sujeto que adopta disposiciones o rasgos personales y se vincula genuinamente a normas como estrategia para, a largo plazo, maximizar su utilidad. De esta forma, este homo sapiens renuncia a tomar las decisiones sobre la base de lo que en un caso concreto, y consideradas todas las circunstancias, promoveria en mayor medida sus intereses (que es lo que haría un maximizador situacional de utilidad).

¿En quế sentido podría ser beneficioso $y$, por tanto, racional para un actor renunciar a maximizar situacionalmente su utilidad? Las ventajas de la estrategia del maximizador disposicional de utilidad son las que se derivan de la capacidad de vincularse pro fufuro a determinados comportamientos, con independencia de si en ese momento serán o no los que maximicen su utilidad. Típicamente, estas ventajas se concretan en la posibilidad de participar en la consecución y el disfrute de bienes colectivos. Como es sabido, en este ámbito se producen con frecuencia situaciones del tipo dilema del prisionero, en las que precisamente el seguimiento consecuente de la racionalidad individual hace fracasar un empeño colectivo que redundaria en beneficio de todos los participantes. Para evitar este riesgo, en ocasiones cabe crear una estructura de control que dificulte la proliferación de free riders y demás conductas no cooperativas, pero ello conlleva normalmente altos costes y hace disminuir correlativamente la eficiencia de la organización colectiva. En este sentido el autor llama empresas cooperativas a las organizaciones que se basan en la cooperación y disposición de rendimiento voluntario de, al menos, una parte de sus miembros, y que, por tanto, tienen por definición un problema interno de control.

Pues bien, los maximizadores situacionales no son miembros adecuados para este tipo de empresas, pucsto que en cuanto tengan oportunidad de extraer una ventaja personal y el riesgo de ser descubiertos sea escaso, adoptarán una conducta no cooperativa. En cambio, sí resultan ser socios fiables a la hora de desarrollar una empresa cooperativa los maximizadores disposicionales de utilidad, en tanto personas sometidas a reglas morales que les preservan de caer en las tentaciones no cooperativas.

Para tener una idea de la importancia real de este tipo de empresas cooperativas hay que recordar que no sólo se trata de empresas de tipo económico: pueden ser también de tipo político, social, ideológico o religioso. Cualquier asociación, incluida la unión con el fin de formar familia, constituye una empresa cooperativa en este sentido. Por tanto, existe sin duda una demanda de personas cuya sujeción normativa permita una asociación fructífera. El maximizador disposicional de utilidad puede ver así recompensada su sujeción normativa, al tiempo que un maximizador situacional de utilidad tendrá serias dificultades para ser aceptado en empresas cooperativas. De ahí que un individuo racional que desee satisfacer en la mayor medida posible sus intereses tenga buenas razones para incorporar a su elenco de estrategias el de no actuar únicamente como homo economicus, sino también como homo sapiens.

¿Es empíricamente plausible este modelo de comportamiento? Desde luego no lo es menos que el del homo economicus. Hay muchas ocasiones en las que las personas no actúan como decisores consecuencialistas, sino que siguen sin mayor reflexión reglas convencionales y morales. En este sentido, un modelo que prevea la posibilidad de optar por dos estrategias de decisión, una consecuencialista y otra sujeta a roglas, se encuentra incluso más cercano a la realidad que el modelo del homo economicus.

Lo que puede parecer, en cambio, menos plausible es que rasgos personales tales como la sujeción a normas morales sean algo que se pueda adquirir como 
resultado de un cálculo estratégico. Parece más bien que van formándose con el tíempo y de modo inconsciente. No obstante, como han puesto de manifiesto autores como J. Elster y R. Axelrod ${ }^{\text {, }}$, es en principio concebible un cambio de personalidad no deliberado y, sin embargo, ajustado a los intereses personales, que operaría a través de un proceso evolutivo de adaptación y selección. Según esta explicación, los rasgos personales que resultan beneficiosos se reforzarían con el tiempo, y aquellos que obstaculizan los intereses de un determinado individuo se debilitarían, sin que ello tuviera que ser el producto de una decisión deliberada ${ }^{6}$.

\section{II. ¿Merece la pena simular} ser un maximizador disposicional?

Hasta aquí se ha justificado en qué medida adquirir la condición de un maximizador disposicional de utilidad puede promover los intereses de un actor: en cuanto le convierte en idóneo para participar en empresas cooperativas a las que un maximizador situacional tiene vedado el acceso. Pero, naturalmente, el problema fundamental que se plantea en sociedades abiertas caracterizadas por interacciones con sujetos cambiantes y anónimos es el de cómo identificar al maximizador disposicional de utilidad que se está demandando. Porque si no fuera posible identificar con cierto grado de certeza a este tipo de personas, lo único que se habría probado es que existen fuertes incentivos para simular ser un maximizador disposicional, sin por ello renunciar a las ventajas del cálculo situacional y oportunista de qué decisión actual favorece en mayor medida los propios intereses. Es más, en tal caso, quien estuviera a la busca de socios cooperativos no tendría tampoco ninguna razón para fiarse de las apariencias, y por tanto volveríamos a la situación dilemática inicial.
No obstante, para Baurmann los costes y los riesgos personales derivados de una vida como simulador podrían ser en ocasiones tan altos que hicieran recomendable no sólo parecer, sino realmente ser un maximizador disposicional. Y en tal caso también sería racional por parte del demandante de socios cooperadores confiar en la apariencia de que un determinado actor es una persona que se guía por normas morales. Si, en efecto, dichos costes y riesgos son tan altos como para convertir una estrategia de simulaciốn en errónea, es algo que no cabe dilucidar de una vez por todas, sino que dependerá del contexto cmpírico de los actores.

Desde luego, los costes de un simulador no son escasos: en primer lugar, la necesidad de distinguir cuidadosamente entre buenas oportunidades para aprovecharse y trampas en las que su condición de simulador puede quedar al descubierto. $Y$ en segundo lugar, el notable inconveniente de no poder mantener relaciones humanas auténticas con los demás socios cooperadores, que normalmente serán personas con las que se mantenga un contacto regular y temporalmente extenso. Tambiên los riesgos de la estrategia simuladora son notables si tenemos en cuenta que en principio basta con ser descubierto una sola vez en una conducta no acorde con la condición de persona íntegra para arruinar en buena medida la reputación trabajosamente lograda. Por tanto, el riesgo equivale a la probabilidad de ser descubierto una sola vez, de tomar una sola vez una decisión errónea sobre cuándo aprovecharse de la apariencia creada o de dejar traslucir una sola vez, incluso mediante sintomas secundarios, que no se es realmente como se aparenta ser. $Y$ las consecuencias de esa pérdida de reputación pueden ser sumamente graves si suponen no sólo ser excluido de la empresa cooperativa en cuestión, sino también ver cerradas las puertas a otras empresas cooperativas que tengan noticia del hecho. Porque una de 
las características de las empresas cooperativas es que, para bien o para mal, es mucho más fácil adquirir informaciones relevantes sobre la reputación que una persona se ha labrado en esa empresa que sobre su conducta en cualesquiera interacciones individuales esporádicas. En este sentido, la participación en empresas cooperativas convierte al individuo en menos opaco.

En consecuencia, puede desde luego haber situaciones en las que sea más inteligente optar por ser realmente virtuoso que no asumir la ardua tarea de la simulación. La evidencia empírica de que en el mundo hay un gran número de personas deshonestas no absta a este análisis ni a la posibilidad de que existan empresas cooperativas fructíferas. Todo lo que para ello se requiere es que la relación entre personas para las que resulte racional la estrategia simuladora y personas para las que resulte más inteligente ser cooperadores integros se mantenga en un equilibrio que no amenace el objetivo final de la empresa.

\section{Los presupuestos de la estrategia cooperativa}

Hasta el momento, Baurmann ha logrado hacer plausible que adquirir determinadas virtudes y vincular la propia conducta a normas morales puede ser, bajo determinadas condiciones, una buena estrategia de maximización de la utilidad individual. Pero puesto que esas condiciones se dan sólo en las empresas cooperativas, queda por explicar en qué medida esa conducta virtuosa puede extenderse más allá del estricto ámbito empresarial, favoreciendo el mantenimiento de las instituciones centrales de la sociedad liberal. Ello equivale a preguntar por el alcance de las normas morales a las que se vinculará el maximizador disposicional.

En principio, un actor racional no tiene por qué extender ese alcance fuera del ámbito cooperativo objeto de su interés. Bastará con que limite el alcance al grupo de sus socios cooperativos, esto es, que formule las condiciones de aplicación de la norma de forma tal que sólo incluya como beneficiarios a esos mismos socios. Es más, puede tener interés en mantener esta virtud selectiva para beneficiarse hacia fuera de una actitud depredadora. Lo aconsejable podría ser, pues, adherir a una determinada moral de grupo. Las pautas de comportamiento válidas entre los miembros de un clan mafioso pueden ser un buen ejemplo de una moral gnupal de este genéro.

Sin embargo, a la hora de formular las condiciones de aplicación el empresario deberá tener presente que en el futuro su círculo de cooperación puede cambiar, y que en ese sentido no parece conveniente configurar las condiciones de aplicación de modo excesivamente cerrado. El grado de amplitud aconsejable dependerá naturalmente del contexto social en el que se encuentre. En una sociedad cerrada, en la que existe poca movilidad social, el maximizador disposicional puede prever con cierto grado de certeza cuáles son los sujetos que en el futuro pudieran resultar interesantes como cooperadores. En este sentido podría limitar los beneficios de las normas a las que se vincula a cierta clase de individuos, sin excesivo riesgo de dejar fuera a personas que en el futuro pudicran ser valiosas para él.

Pero en una sociedad abierta, caracterizada por una fuerte individualizacion, en cl sentido de que no existe ya una concxión indisoluble entre las perspectivas de vida del individuo y su pertenencia a un determinado colectivo, se convierte en sumamente dificil el establecer unas condiciones de aplicación de las normas morales restringidas a determinada clase de personas, puesto que el empresario no puede confiar en que sus potenciales colaboradores vayan a seguir reclutándose en el futuro siempre de esa clase y sólo de esa clase. Si se dan las condiciones del tipo ideal de 
sociedad abierta, al cmpresario le va a resultar prácticamente imposible encontrar un criterio de discriminación entre potenciales cooperadores y aquellos que no es preciso tomar en cuenta. O lo que es lo mismo, va a tener buenas razones para optar por una formulación no restringida, sino general de las normas a las que se adhicra, y por buscar sus socios entre personas que igualmente favorezcan este tipo de normas no discriminadoras. De esta manera, en una sociedad abierta podría jugar una mano invisible que haria que un maximizador racional de utilidad, en tanto empresario cooperativo, actuara como si persiguiera intereses generalizables cuando su interés real se limita a sus actuales y futuros colaboradores.

Ahora bien, esto es lo que sucede en la sociedad abierta entendida como tipo ideal. En una sociedad real el funcionamiento de dicha mano invisible dependerá de la relación que haya entre intereses de cooperación e intereses de explotación. Porque si en un determinado ámbito predominan los intereses de explotación, el maximizador disposicional de utilidad tendrá una buena razón para preferir normas particulares. Esta relación depende a su vez del poder que tenga una empresa. Cuanto más poderosa sea en relación con su entomo, tanto menos dependerá de relaciones externas cooperativas y más podrá basar su estrategia en la explotación. Por ello, la única forma de reducir los incentivos de los empresarios para adoptar una estrategia no cooperativa es mantener limitadas las diferencias de poder existentes en una sociedad, de modo tal que las empresas más poderosas no puedan utilizar ese poder para someter a las cmpresas y los miembros de la sociedad más débiles.

La existencia de un Estado que asuma el máximo poder de una sociedad no soluciona por sí sola el problema. Porque el Estado no es en este sentido sino una empresa más que, si su poder es excesivo, puede ser utilizada para favorecer los inte- reses personales de los maximizadores de utilidad en tanto agentes estatales. Por ello, lo decisivo es que las empresas más poderosas no sean tan fuertes como para poder imponerse a la acción conjunta de los demás miembros de la sociedad. De esta forma podrán encontrar resistencia si intentan imponer unilateralmente sus intereses. En la medida en que se consiga esta relativa neutralización de las relaciones de poder tenderán a aumentar los intereses de cooperación sobre los intereses de explotación.

Pero incluso en una sociedad abierta, con relaciones neutralizadas de poder, cabe de nuevo la posibilidad de aparentar una tendencia cooperativa para, clandestinamente, tener una actitud depredadora. Que ello sea una buena estrategia dependerá naturalmente de la eficacia de los controles sociales que puedan desenmascarar este doble juego.

En definitiva, se tienen que dar las siguientes tres condiciones para que un empresario tenga razones para preferir una estrategia cooperativa:

1. ${ }^{\text {Q }}$ Que cxista una sociedad abierta con libertad de asociación y buenas perspectivas de ganancia para una conducta cooperativa.

2. ${ }^{a}$ Que las relaciones de poder estén neutralizadas de tal forma que a las empresas más poderosas no les valga la pena practicar abiertamente una estrategia no cooperativa.

3. Que exista un sistema eficaz de control social que disuada de elegir una estrategia no cooperativa oculta.

Bajo estas condiciones, pues, el empresario tendrá razones para no preferir normas particulares sino generales, $o$, lo que es lo mismo, para, en defensa de sus propios intereses, defender intereses universalizables. $Y$ es este excedente moral el que para Baurmann puede satisfacer la demanda moral de una sociedad en su conjunto. 


\section{Los principios generales de respeto interpersonal y de equidad social}

Un razonamiento análogo al que se ha seguido en cuanto a la extersión de las normas promovidas por el maximizador disposicional de utilidad es también válido para el contenido de esas normas. Porque un argumento contra la tesis de la autosostenibilidad moral de la sociedad liberal podría ser que un empresario cooperativo no tiene interés más que en los contenidos que afecten a su propia empresa. La solución a este problema viene dada por la estructura y el tipo de normas o, mejor dicho, del conjunto de normas en el que estará interesado el empresario.

Porque el empresario cooperativo, en tanto creador de normas, tiene buenas razones para establecer no sólo un catálogo de reglas precisas, sino para completarlo con principios generales y abstractos. $Y$ ello por los problemas de infrainclusión y sobreinclusión de los que toda regla adolece $^{7}$. Para evitar aplicaciones ciegas de las reglas a casos para los que en realidad no estaban pensados y para garantizar su aplicación en casos no previstos, pero en los que el bien de la empresa exigiría esa aplicación, el empresario estará interesado en que sus socios cooperativos estén subordinados no a un mero conjunto de prescripciones particulares, sino a un orden normativo. Lo que equivale a decir que no sólo esperará de sus socios el respeto a determinadas reglas morales, sino que estén en posesión de una identidad moral que dote de coherencia a este conjunto de reglas y guíe la conducta de los socios incluso cuando las reglas existentes se revelen inadecuadas. Pues bien, para Baurmann es posible concretar en dos principios últimos las generalizaciones de las normas favorecidas por el empresario cooperativo: un principio de respeto interpersonal, que consiste en que un actor debe considerar y respetar los intereses individuales de otras personas en la medida en que desea la consideración y el respeto de sus propios intereses individualcs, y un principio de equidad social, conforme al cual un actor debe participar con una contribución adecuada en la producción de un bien si, y sólo si, los costes individuales de la propia contribución a este bien colectivo son superados por la utilidad individual que obtiene directa o indirectamente de este bien.

Merced a estos dos principios se supera la cesura entre las normas que sólo tienen importancia dentro de una empresa y las normas genuinamente morales que son relevantes para el grupo social más amplio. $Y$ ello porque un empresario cooperativo que aspire a la mayor protección posible de sus propios intereses exigirá de los socios de su empresa disposiciones de conducta que automáticamente protegen también los intereses de otras personas y, en este sentido, son morales. Si se cumplen las condiciones intra y extraempresariales mencionadas el maximizador disposicional de utilidad habrá adquirido así, finalmente, una genuina personalidad moral.

\section{La implicación recíproca de sociedad liberal y mercado de la virtud}

Ahora bien, si el mercado de la virtud, necesario para que una sociedad liberal no termine por destruir su propio fundamento moral, depende a su vez de condiciones tales como la existencia de una sociedad abierta, unas relaciones de poder neutralizadas y un sistema eficaz de control social que eleve a un nivel suficientemente alto los riesgos de un comportamiento desviado oculto, entonces parece que nos encontramos ante un problema de circularidad: el mercado de la virtud precisa de un orden social liberal para poder funcionar, y éste, a su vez, requiere de un mercado de la virtud para subsistir.

Naturalmente, esta relación de implicación reciproca no supone un problema 
explicativo una vez que ya están dados tanto una sociedad abierta como un mercado de la virtud. Lo que hay entonces es un reforzamiento mutuo entre el mercado de la virtud y las condiciones en las que se sustenta. Si un mercado de la virtud ya existe, entonces por definición se produce un número suficientemente alto de personalidades morales para garantizar la producción de bienes públicos, entre los que destacan, por su importancia, las instituciones centrales de una sociedad liberal. $Y$ éstas, a su vez, facilitan la reproducción del mercado de la virtud. Por lo demás, este resultado teórico coincide con lo que indica la experiencia histórica: si una democracia liberal se ha podido mantener durante algún tiempo, entonces suele poder mantenerse por su propia fuerza, y generalmente aumentan su estabilidad y resistencia.

Ello no significa, por supuesto, que ese orden social sea invulnerable. Uno de los peligros principales consiste en el hecho de que, justamente por esa tendencia autorreforzante, se relaje el control social ejercido y se subestime su función. Esta falta de atención es corregible si se advierte a tiempo, pero puede suceder también que la actitud cooperativa caiga por debajo de un límite crítico, y las instituciones estatales y juridicas estén tan infiltradas y corrompidas que no sea ya posible contener su decadencia. En este caso, la espiral ascendente, reforzadora, se habria transformado en una espiral descente y destructiva.

Pero donde la mencionada relación de implicación recíproca sí plantea un problema de circularidad es a la hora de explicar cómo han podido surgir esa sociedad abierta y ese mercado de la virtud. La salida a este problema estriba en demostrar que las condiciones de funcionamiento del mercado de la virtud pueden desarrollarse también sin la previa existencia de éste. $Y$ en este sentido Baurmann se refiere a las excepcionales circunstancias históricas en las que surgieron en Europa, en primer lugar, un sistema de dominación no despótico y, al final de un largo proceso aperturista, también las instituciones de una sociedad liberal. En apretada síntesis, se trata de la constelación histórica en la que muchos pequeños Estados, de similar poder y culturalmente cercanos, competían entre sí y tenían que ofrecer a sus súbditos condiciones de vida atractivas para conseguir su apoyo y no arriesgarse a que éstos emigraran a territorios más favorables. Los espacios de inmunidad y libertad concedidos reforzaron a su vez los intereses en el mercado y en la cooperación, al tiempo que limitaban el ejercicio arbitrario del poder, limitación exigida también por el interés de los propios detentadores del poder en una economía floreciente. De esta forma se fueron desarrollando las condiciones de una sociedad abierta en la que los ciudadanos podían perseguir sin excesivas trabas sus intereses económicos y sus objetivos empresariales, al amparo de un sistema de control social suministrado por el aparato estatal.

Se sentaron así las bases de la emergente burguesía. Pero las condiciones sociales marco favorables a los intereses de la clase burguesa son, al mismo tiempo, las condiciones favorables para el mercado de la virtud. Los representantes de la burguesía, al aspirar, sobre todo desde el punto de vista de sus objetivos económicos, a una sociedad abierta con relaciones neutralizadas de poder y un sistema eficaz de control social, habrán de ampliar no sólo el mercado económico, sino también el mercado de la virtud, extendiéndolo a un número cada vez más amplio de personas. De esta manera ponen en marcha un proceso en cuyo final puede encontrarse no sólo un mercado de la virtud, sino también una sociedad liberal.

Esta explicación demostraria, pues, que en principio es posible que se generen las condiciones para que pueda crearse un mercado de la virtud. Que ello haya sido 
históricamente un acontccimiento excepcional no va en detrimento de la teoría. Es que, de hecho, el surgimiento de las instituciones liberales es un acontecimiento sumamente improbable. Lo normal en términos históricos es la existencia de relaciones desiguales de poder en sociedades cerradas, en las cuales los poderosos no tienen ninguna razón y los sometidos ninguna oportunidad para iniciar un cambio ${ }^{8}$

\section{V1. La fundamentación de una moral universal y el mito de la comunidad}

Hasta aqui, Baurmann ha tratado de desmontar la tesis del carácter autodestructivo del orden liberal. Es desde luego cierto que este orden destruye en buena medida lazos sociales y dinamita los vínculos grupales del individuo. Pero es que esa liberación del individuo de lazos y relaciones tradicionales es precisamente la condición necesaria para que pueda embarcarse libremente en empresas cooperativas con las personas más adecuadas para sus fines, intereses y preferencias. $Y$ a la postre es la demanda de personalidades morales e integras originada por las empresas cooperativas la que puede generar la virtud cívica y el compromiso público de los ciudadanos necesarios para sostener las instituciones liberales. De esta forma, la vieja visión del liberalismo, que prometía prosperidad colectiva, dominación controlada e integridad moral del individuo a partir de la libre persecución de los propios intereses, adquiere una nueva base: no es el mercado económico quien puede lograr este prodigio, sino el mercado de la virtud. En definitiva, se pone de relieve que una sociedad liberal no nccesariamente ha de provocar una crisis moral ni precisa urgentemente de una restauración de valores comunitarios.

Pero el autor va más allá de esta respuesta al reto comunitarista. Pasando a la ofensiva, su análisis de qué alcance de las normas morales será favorecido según nos encontremos ante una sociedad cerrada o abierta le permite impugnar lo que llama el mito de la comunidad. Se trata de una perspectiva muy difundida, que contrapone la imagen de una pequeña comunidad, con relaciones y lazos personales fuertes $y$ estables que fundamentan una actitud de mutua coopcración y solidaridad, a la imagen opuesta de la fría e impersonal sociedad urbana, en la que predominan el anonimato y la indiferencía frente a los demás individuos. Conforme a esta percepción, el individuo sólo podría estar normativamente sujeto en la comunidad, mientras que la sociedad urbana tendería a convertirse en una jungla llena de individuos anómicos. Este mito de la comunidad es acertado en un aspecto: en una sociedad plenamente secularizada sólo existe una base firme para la conducta moral si no se trata de una masa amorfa, desestructurada de individuos. Sin empresas cooperativas que la vertebraran, el escenario social podría ciertamente asemejarse mucho a una jungla. Pero el error de esta visión consiste en su promesa de que la pequeña comunidad garantiza una sujeción del individuo a normas morales. Porque es desde luego cierto que en el seno de pequeños grupos cerrados suele darse un alto grado de lealtad y solidaridad frente a los otros miembros del grupo. Pero si su vida y sus expectativas se mantienen dentro de ese grupo, ¿qué razón podría tener un individuo para promover una moral taniversalista, que tuviera también en cuenta los intereses de las personas externas a ese grupo? Una sociedad cerrada favorece, pues, una moral restringida, una moral del ingroup. Por ello, concluye Baurmann, justamente la sociedad moderna, con su anonimidad y movilidad, $\tan$ frecuentemente lamentadas, constituye el fundamento irrenunciable para el establecimiento empírico de una moral universalista que responda a nuestra concepción ética contemporánea y que, por lo demás, 
resulta indispensable para el mantenimiento de una sociedad liberal.

$Y$ de nuevo este resultado del análisis parece coincidir con la experiencia histórica. Porque la existencia de una moral interna estable en comunidades firmemente estructuradas no parece haber sido nunca un impedimento serio para una actitud depredatoria hacia quienes no pertenecian a la propia comunidad. Por cllo, lo que precisa explicación, en términos históricos, no es cómo es posible que se establezca una moral restringida, sino cómo es posible que surja y se vaya imponiendo una moral universal y de alcance ilimitado. En definitiva, la inexistencia de límites en las relaciones sociales y en las normas morales debe considerarse un producto artificial y frágil del desarrollo histórico hacia una sociedad abierta.

\section{VII. ¿En qué medida vivimos en una "sociedad abierta"?}

El cuidadoso análisis de Baurmann de las condiciones bajo las cuales una sociedad liberal puede generar el compromiso cívico y la moral de sus ciudadanos que resultan indispensables para su propia supervivencia suscita algunas interrogantes: la principal es la de si el funcionamiento de nuestras sociedades contemporáneas se adecua en suficiente medida al modelo de sociedad abierta por él descrita, con plena libertad de asociación, relaciones neutralizadas de poder y un control social suficientemente intenso como para desincentivar la simulación.

¿Cabe decir que en nuestra realidad social predominan ya realmente los intereses de cooperación sobre los intereses de explotación? ¿Rcalmente se han desvanecido ya hasta tal punto los lazos que permiten identificar a un individuo por su pertenencia a determinados grupos o clases sociales, cxiste ya tal movilidad social que constituya una mala estrategia, pon- gamos por caso, para un o una joven estudiante de Derecho o Económicas del barrio de Salamanca, ir desarrollando un tipo de «moralidad» restringida a los intereses de las personas pertenecientes al mismo o similar entorno social? Un defraudador de impuestos, $i$ de verdad no puede ser un socio leal y fiable de una determinada empresa cooperativa? iEs convincente el argumento de la extensión de las normas morales que protegen los bienes de la empresa cooperativa a la protección de cualesquiera otros bienes colectivos con el fin de proteger los eventuales intereses futuros de la propia empresa?

La lista de dudas podría prolongarse aún, pero creo que son ya suficientes para ver que confluyen todas cn un mismo punto: en que no parece fuera de toda discusión que la cualificación para participar en determinadas empresas colectivas implique, por sí misma, un compromiso con el sostenimiento de bienes colectivos más amplios, como son las instituciones del orden social liberal. Y ello porque la participación individual en empresas cooperativas estấ mediada, cuando menos, por la pertenencia a grupos sociales que se definen por su extracción socioeconómica; normalmente, un individuo pertenccicntc a la clase media alta urbana va a reclutar los socios para cualesquiera empresas cooperativas de entre los integrantes de esa misma clase. $\mathrm{Y}$ por tanto, 10 que se va a exigir a un socio cooperativo no es lealtad a cualesquiera empresas colectivas, sino a los intereses de ese grupo social de referencia. Esto es, lo que creo que Baurmann no ha conseguido acreditar convincentemente es cómo se supera la censura entre los intereses de un conjunto limitado de empresas cooperativas y otros bienes colectivos de ámbito más amplio, entre las normas morales restringidas a las que se tienen que adherir los socios cooperativos para que su propia empresa salga adelante $y$ unos principios generales de respeto interpersonal y equidad social. 
Ahora bien, este razonamiento sirve para impugnar la tesis empirica de que hayamos logrado ya una sociedad abierta en la que el mercado de la virtud pueda funcionar a la perfección. En cambio, no cuestiona, antes bien presupone, la validez del análisis teórico de Baurmann. Porque lo que estoy afirmando no es sino que la existencia de grupos socioeconómicos de referencia obstaculiza el normal funcionamiento del mercado de la virtud. Igual que sucede con el mercado económico, en el mercado de la virtud hay en este sentido tendencias que desvirtúan la libre competencia moral y la formación de individuos genuinamente morales. De no existir estos obstáculos sí que podría cxistir una perfecta identidad entre cl sujeto moralmente idóneo para la participación en empresas cooperativas y el sujeto moralmente comprometido con cl sostenimiento de las instituciones sociales de ámbito más general.

Pero entonces, en la medida en que estas desvirtuaciones existen, üla tesis comunitarista del carácter moralmente autodestructivo de la sociedad liberal estaría justificada? Creo que ésa sería una conclusión precipitada. Porque, en contra de lo que parece sostener Baurmann, para invalidar esa tesis no es realmente necesario que un número suficiente de ciudadanos se adhiera a normas morales que tengan en cuenta los intereses de todos, sino que basta con que los miembros de algún o algunos gnupos sociales de referencia suficientemente amplios y relevantes tengan entre sus intereses comunes el sostenimicnto del propio orden social liberal. Si lo que se exige a los socios cooperativos es un compromiso moral con los propios intereses colectivos, en cuanto pueden ser o llegar a ser relevantes para la empresa cooperativa, y dicho orden social forma parte de esos intereses colectivos, entonces el compromiso moral tendrá que hacerse extensivo a êl. Por tanto, no es necesario sostener una conexión entre idoneidad para la participación en empresas colectivas y genuina personalidad moral para defender la tesis de la autosostenibilidad moral de la sociedad liberal. Es suficiente con una conexión entre idoneidad participativa y compromiso moral con los demás intereses comunes del grupo social de referencia, externos a la propia empresa cooperativa, siempre y cuando las personas interesadas en el orden social liberal tengan suficiente poder como para imponerlo a quienes no tengan razones para defenderlo.

$Y$ bien mirado, ésa parece ser la actual situación en las llamadas sociedades occidentales de dos tercios. Por supuesto que nadie defiende abiertamente una formulación restringida de las normas morales. Pero aquí no estamos hablando de cómo se enuncia determinada norma moral, sino de la moralidad positiva, de la empíricamente vigente. $Y$ en este sentido creo que es claro que a la hora de distribuir los beneficios de esa gran empresa cooperativa que es el orden social los intereses del tercio marginado no cuentan, o en todo caso no cuentan en la misma medida en que cuentan los intereses de los otros dos tercios. Pero es que ese tercio tampoco es necesario para el mantenimiento del orden social establecido. El análisis de Baurmann de las condiciones para el establecimiento empírico de una determinada moral parece tener, por tanto, un potencial explicativo que trasciende a sus propias conclusiones.

Por lo demás, podría todavia suscitar dudas su afirmacion de que, en general, habrá suficientes casos en los que sea realmente más racional ser un individuo moralmente íntegro que simular serlo para aprovecharse luego de modo oportunista de la confianza generada. Pero no creo que esta objeción ponga en graves aprietos la tesis desarrollada, por cuanto no sostiene que la existencia de un número suficiente de ciudadanos que contribuya equitativamente al sostenimiento de las instituciones liberales sea una consecuencia necesaria del orden liberal y de la existencia de 
empresas cooperativas. Antes bien, Baurmann muestra las condiciones empiricas de las que dependerá este hecho, tales como el control social existente y el uso que se haga de mecanismos para incentivar la integridad y desincentivar la simulación. $Y$ deja también claro que sociedad liberal y mercado de la virtud constituyen bienes artificiales y frágiles que pueden ser des- truidos si no se ascgura en suficiente medida sus condiciones de funcionamiento. El que los ciudadanos recobren de esta manera la responsabilidad por su propio orden social tal vez no sea la menor de las virtudes del libro hasta aqui comentado, basado en un individualismo metodológico abiertamente opuesto a la sociología de orientación holista dominante en Alemania.

\section{NOTAS}

\begin{abstract}
I "Instituciones suicidas" es precisamentc cl titulo de las Segundas Conferencias Aranguren de Filosofia, impartidas por Ernesto Garzón Valdés, en las que analiza el carácter autodestructivo de la democracia y el mercado, y propone establecer una serie de límites éticos a su funcionamiento para neutralizar dicha tendencia; aparecieron publicadas bajo est mismo título en Isegoria, 9 (1994), pp. 64-128.

${ }^{2}$ Michael Baurmann, El mercado de la virtad. Moral y responsabilidad social en la sociedad iberal, traducción de Emesto Garzón Valdes, Barcelona, Gedisa, 1998, 270 pp. Titulo oniginak: Der Markt der Tagend. Moral und soziale Verantwortung in der Iiberalen Gesellschaft, Tubinga: 1. C. B. Mohr (Panl Siebeck), 1996.

3 En lo referente al sistema juridico, ya H. L. A.
\end{abstract} Hart puso de relieve, en El concepto de derecho, gue su mantenimiento exige que al menos algunos de los ciudadanos adopten un punto de vista intemo respecto del Derecho, esto es, que usen las normas juridicas como guta de sus propias acciones y como parámetro de evaluación de las acciones de los demás y que lo hagan voluntariamente, no por la amenaza de coacción inherente al Derecho.

* Este planteamiento se inscribe dentro de una tendencia a armonizar la moralidad individual con la persecución racional de los propios intereses, que cuenta ya con algunos ilustres antecesores, como, por ejemplo, R. H. Frank, The strategic wle of the emotions, Nueva York, 1988, o D. Gauttier, La moral por acuerdo, Barcelona, 1994 [al respecto pueden verse las contribuciones del propio D. Gauthier, M. D. Farrell, R. Zimmerling y A. Calsamiglia en Doxa, 6 (1989)]; del mismo autor acaba de publicarse una colccción de ensayos bajo el título Egoismo, moralidad y sociedad liberal, Barcelona, 1998, comentada por Blanca Roúriguez López en /segoria, 18 (1998), pp. 266-269.

s. Elster, The subvertion of rationality, Nueva York, 1987; R. Axelrod, «An evolutionary approach to norms», en American Polutical Science Review, 1986. pp. 1095-1111.

- Dando un paso más en esta explicación evolutiva recientemente se ha llegado incluso a anclar una generica disposición de sociabilidad en la biologia humana y a tratar de explicar el paulatino desarrollo en el pleistoceno de este instinto social, entendido como dispo. sición tanto para la fidelidad a los compromisos adquiridos como para la detección de simuladores por sus indudables ventajas adaptativas. Vid. Fêlix Ovejero, "Del mercado al instinto (o de los intereses a las pasioness), en Isegoria, 18 (1998), pp. 181-203.

7 Un detenido analisis de csle problema que suscita todo intento de guiar la conducta mediante reglas, en F. Schater, Playing by the rufes, Oxford, 1991.

3 Esta visión de la historia europea es en gran medida tributaria, como señala el propio autor, de los estudios de Max Weber sobre la excepcional via que conduce a que sea precisamente en Europa donde se desarrolle el capitalismo racional de la moderna sociedad occidental. Se ha hablado, en este sentido, del milagro europeo. Así, en el estudio macrohistórico de Eric Lionel Jones, que lleva precisamente por título El milagro europeot entorno, economía y geopolitica en la historia de Europa y Asia, Madrid, 1990. O cuando Emest Gellner señala que *tal vez no sea la ausencia de transformaciones de base lo que precise de una explicación, sino s6lo el milagro de Europam. 